

\title{
School Practices In The Colégio Americano: an Approach to Material Culture
}

\begin{abstract}
This article addresses school practices and material culture in school in Belém Do Pará at the end of the nineteenth century. The objective is to analyze how material culture and school practices were articulated at the Colégio Americano, conceived by José Veríssimo between 1884 and 1890. The work Noticia Geral sobre o Collegio Americano is used as a source of information. The methodology used comprises a hermeneutic-historical approach. When analyzing the material culture of the school, the outlook includes a perception of its links with the historical, cultural and social context where a new model of education highlighting civility, nation and moral was created. Consequently, such devices were not just simple objects, but they revealed the conflictual or peaceful relations of this context, and even the school practices in the institution. It is observed that, for its creator, the use and the description of the objects placed in the Colégio Americano structure were intended to establish and maintain standards that should form disciplined men. They should be directly linked up with the purpose of physical, moral and civic education of students.
\end{abstract}

Keywords: history of education, school practices, school culture, material culture.

\section{Pratiques Scolaires Dans le Colégio Americano: une Approche de la Culture Matérielle}

\section{Résumé}

Cet article aborde les pratiques scolaires et la culture matérielle de l'école à Belém Do Pará, à la fin du XIXe siècle. L'objectif est d'analyser la façon dont la culture matérielle et les pratiques scolaires se sont articulées dans le Colégio Americano, conçue par José Veríssimo entre les années 1884 et 1890. On utilise comme source d'information l'œuvre Noticia Geral sobre o Collegio Americano. La méthodologie utilisée est historique et herméneutique. Au moment d'analyser la culture matérielle de l'école, on a comme horizon la 
perception de ses liens avec le contexte historique, culturel et social pendant lequel un nouveau modèle d'éducation soulignant la civilité, la nation et la morale a été généré. Par conséquent, tels appareils n’étaient pas de simples objets, mais ils ont dévoilé les relations conflictuelles ou pacifiques de ce contexte-là, ou encore les pratiques scolaires dans l'institution. On observe que, pour son créateur, l'usage et la description des objets disposés sur la structure de le Colégio Americano avaient pour but d'établir et de maintenir des normes qui devaient forger des hommes disciplinés. Ils devaient être liés directement avec l'objectif de l'éducation physique, morale et civique des apprenants.

Mots-clés: histoire de l'éducation, pratiques scolaires, culture scolaire, culture matérielle.

\section{As Práticas Escolares no Colégio Americano: Um Enfoque na Cultura Material}

\section{Resumo}

Neste artigo abordamos sobre as práticas escolares e a cultura material escolar em Belém do Pará, no final do século XIX. Objetiva-se analisar como se configurou a cultura material e as práticas escolares no Colégio Americano, idealizado por José Veríssimo em 1884 a 1890. Utiliza-se como fonte a obra Noticia Geral sobre o Collegio Americano. A metodologia adotada foi a histórico-hermenêutica. Ao tomarmos como análise a cultura material escolar, tem-se como horizonte a percepção das suas articulações com o contexto histórico, cultural e social em que foi engendrado um novo modelo de educação que enfatizava como importante os aspectos da civilidade, da nação e da moral. Logo, tais artefatos não seriam simples objetos, mas revelam as relações conflituosas ou pacíficas daquele contexto, inclusive as práticas escolares da referida instituição. Observa-se que a utilização e descrição dos objetos dispostos na estruturação do Colégio Americano, para o seu idealizador, tinha como objetivo estabelecer e realizar a manutenção de normas que deviam formar homens disciplinados, estando diretamente articulados com as intenções de educação física, moral e cívica dos alunos.

Palavras-chave: história da educação, práticas escolares, cultura escolar, cultura material. 


\section{Introdução}

O presente artigo aborda sobre a cultura material escolar e as práticas escolares em Belém do Pará, em finais do século XIX, enfocando a análise no Colégio Americano, idealizado por José Veríssimo em 1884 a 1890. José Veríssimo Dias de Matos nasceu em Óbidos/Pará em 1857. Estudou no Rio de Janeiro e desenvolveu boa parte de suas atividades em Belém, onde fundou e dirigiu o Colégio Americano, em 1884. As proposições de José Veríssimo são de matriz positivista e evolucionista, em que no Colégio Americano, tais ideais são praticados a partir de uma noção ligada aos preceitos de higiene, tendo como objeto de suas ações não somente o corpo, mas também a mente e a moral da criança e dos jovens de até 16 anos de idade.

O enfoque metodológico baseia-se na pesquisa bibliográfica e documental, no qual tomamos como fonte a obra Noticia Geral sobre o Collegio Americano fundado e dirigido por José Veríssimo em Belém do Pará de 1888. Objetivouse identificar de que forma se configura a cultura material escolar e as práticas escolares no Colégio Americano em Belém do Pará no final do século XIX, bem como a materialidade dos objetos descritos na referida obra.

Ao tomarmos como análise a cultura material escolar do Colégio Americano, tem-se como horizonte a percepção das suas articulações com o contexto histórico, cultural e social em que foi engendrado um novo modelo de educação que enfatizava como importantes os aspectos da civilidade, da nação e da moral. Compreende-se que os artefatos não seriam simples objetos, mas sim revelam as relações conflituosas ou pacíficas daquele contexto (Julia, 2001).

Ao longo das análises constatou-se a existência de uma organização própria, no qual se extraiu os seguintes aspectos: 1) discurso pedagógico — como atente e pretende praticar o Colégio Americano-, 2) encerramento das aulas, 3) notas e boletins, 4) enxoval, 6) horário geral —entradas e saídas-, e 7) cuidados hygienicos. Portanto, observa-se que a utilização e descrição dos objetos dispostos na estruturação do Colégio Americano, para o seu idealizador, intencionava estabelecer e realizar a manutenção de normas a fim de formar alunos disciplinados, estando diretamente articulados com as práticas da educação física, moral e cívica dos infantes e dos jovens.

\section{Cultura escolar: uma incursão teórica}

Julia (2001) diz que cultura escolar não pode ser estudada sem a análise precisa das relações conflituosas ou pacíficas que ela mantém a cada período 
de sua história, com o conjunto das culturas que lhe são contemporâneas, tais como: a cultura religiosa, a cultura política ou a cultura popular. Poderse-ia descrever a cultura escolar como um conjunto de normas que definem conhecimentos a ensinar e condutas a inculcar, e um conjunto de práticas que permitem a transmissão desses conhecimentos e a incorporação desses comportamentos, normas e práticas coordenadas a finalidades que podem variar segundo as épocas — finalidades religiosas, sociopolíticas ou simplesmente de socialização-.

Dependendo de cada contexto histórico surge a necessidade de interpelar as finalidades da transmissão do conhecimento sociopolítico e sua socialização, que moldam a formação do corpo profissional e dos agentes que são chamados a obedecer a essas ordens dos dispositivos pedagógicos utilizados em cada contexto histórico, a fim de facilitar sua aplicação na formação dos alunos. $\mathrm{O}$ que difunde, para além dos modos de pensar e agir no interior das escolas, um debate amplo no interior das sociedades como um processo de escolarização.

Contudo, as normas e práticas não podem ser analisadas sem se levar em conta o corpo profissional dos agentes que são chamados a obedecer a essas ordens e, portanto, a utilizar dispositivos pedagógicos encarregados de facilitar sua aplicação, a saber, os professores primários e os demais professores. A compreensão de cultura escolar também pode ser relacionada ao funcionamento interno dela, relações estabelecidas entre os diferentes sujeitos e seus espaços, tempos e objetos escolares, dentre os quais destacase as culturas infantis que se desenvolvem nos pátios de recreio e o distanciamento que apresentam em relação às culturas familiares.

Chervel (1990) defendia a capacidade da escola em produzir uma cultura específica, singular e original. Ao discorrer sobre a construção das disciplinas escolares, em particular sobre a ortografia francesa, o referido autor criticava os esquemas explicativos que posicionavam o saber escolar como um saber inferior ou derivado dos saberes superiores, fundados pelas universidades, assim como criticava a noção da escola como simples agente de transmissão de saberes elaborados fora dela, tomando-a enquanto lugar do conservadorismo, da rotina e da inércia. Para ele, a instituição escolar era capaz de produzir um saber específico cujos efeitos estendiam-se sobre a sociedade e a cultura, e que emergia das determinantes do próprio funcionamento institucional.

Segundo Vidal (2005), outra categoria presente na cultura material escolar é o seu reflexo na constituição da cultura escolar. A cultura escolar é um objeto 
de análise tão caro para a História da Educação, principalmente por ser o responsável por estudar as particularidades do universo escolar, ressaltase que são vários os temas e questionamentos que podem ser analisados sob esse viés, como, por exemplo: a constituição do currículo, a formação das disciplinas escolares, o cotidiano institucional, o exercício diário de professores e professoras, alunos e alunas e a materialidade da escola.

Sensibilizado também pelas questões relativas à constituição das disciplinas escolares, mas atuando na intersecção com os estudos sobre currículo, Forquin (1993) caracterizava a cultura escolar como seletiva, no que concerne à cultura social, e derivada, no que tange à sua relação com a cultura de criação ou invenção das ciências fonte. Forquin assim expressa:

A educação não transmite jamais a cultura, considerada como um patrimônio simbólico e unitário eimperiosamente coerente. Nem sequer diremos que ela transmite fielmente uma cultura ou culturas, elementos de cultura, entre os quais não há forçosamente homogeneidade, que podem provir de fontes diversas, ser de épocas diferentes, obedecer a princípios de produção e lógicas de desenvolvimento heterogêneos e não recorrer aos mesmos procedimentos de legitimação. Isto significa dizer que a relação entre educação e cultura poderia ser mais bem compreendida através da metáfora da bricolagem (como reutilização, para fins pragmáticos momentâneos, de elementos tomados de empréstimo de sistemas heterogêneos) do que através da metáfora do reflexo ou da correspondência expressiva. (1993, p. 15)

Ou seja, a educação não se constitui um reflexo direto e fiel da cultura, ou melhor, do que se dá na cultura, haja vista que a cultura escolar é seletiva e derivada. Para Forquin (1993) a cultura escolar era efeito de um trabalho de reinterpretação e reavaliação contínua do que devia ser conservado, ao lado de um movimento de esquecimento de parcelas da experiência humana, que se operava a seleção, na herança cultural, de conteúdos tidos por imprescindíveis à educação do homem e fundamentais à perpetuação da sociedade, incluídos no currículo escolar. Fazia-se acompanhar, ainda, de uma transformação do conhecimento produzido pela academia. E, nesse sentido, não apenas recortava saberes e materiais culturais disponíveis em um dado momento na sociedade, mas efetuava a reorganização e reestruturação desses saberes, perante a necessidade de transposição didática.

Para Viñao (2008) a cultura escolar recobre as diferentes manifestações das práticas instauradas no interior das escolas, transitando de alunos a professores, de normas a teorias. Na sua interpretação, englobava tudo o que 
acontecia no interior da escola. Além de abarcar as mais diversas dimensões do cotidiano da escola e de se desfolhar sobre a sociedade. A cultura escolar, para o autor, variava também de acordo com a instituição investigada, nesse sentido, preferia se referir a mesma como culturas escolares.

Faria (2004), em inventário, evidencia pesquisas realizadas no Brasil sobre esta temática, agrupando diversos eixos que envolvem: saberes; conhecimentos e currículos, espaços, tempos e instituições escolares; materialidade escolar e métodos de ensino. Destaca-se a história da educação voltando-se para os diversos arcabouços teóricos relacionados às diversas abordagens sobre a cultura escolar.

Diante, dos diferentes olhares e vieses nos debates sobre a cultura escolar, que nos afastam de uma delimitação de qual seria o mais adequado ou não, nos apresenta como horizonte as semelhanças e diferenças na construção dos diferentes conceitos, demonstrando as práticas de pesquisa e os objetos históricos investigados pelos autores, servindo de alerta à sua incorporação nos estudos no Brasil, haja vista que nos orienta a estar atentos às diversidades culturais, sociais e históricas da escolarização entre os diferentes países.

\section{Práticas escolares e cultura material}

O tratamento científico para a pesquisa histórica das práticas escolares, têm despertado grandes questionamentos, principalmente quando se intenciona falar da prática de outra forma que não seja de maneira negativa, quando se pretende investigar o interior da escola, evitando análises que deslizem para o anacronismo, concebendo o passado na sua identidade com o presente.

De acordo com Bencostta (2013), no bojo desta discussão, observa-se a importância das ações que garantem a integridade dos bens materiais nas novas formas de entendimento dos vínculos existentes entre escola e cultura. Pesquisas atuais, tem identificado e analisado objetos escolares, livros didáticos, arquitetura escolar, equipamentos escolares, etc., utilizando a noção de cultura material escolar para compreender e trabalhar suas interpretações.

A. Chartier (2000) destaca a importância de investigar os fazeres ordinários, pois compreendia que a escola fazia-se ausente exatamente naquilo que exercia: a prática escolar, pois concebia que não se podia ler diretamente a alteridade cultural nos objetos, mas em seus usos, e que a lógica do fazer era oposta à lógica dos fatos. 
Na concepção de de Certeau (1994), o autor criticava a visão empobrecedora dos indivíduos como meros consumidores de bens e sentidos, supostamente passivos e disciplinados. No destaque às práticas ordinárias, os mecanismos de poder e subversões no âmago dos fazeres sociais e históricos. Os dispositivos de poder constituíam o espaço no qual transitavam os sujeitos. Esse espaço podia ser entendido com o institucional —a escola—; o lugar físico —a sala de aula, a carteira do aluno, ou a folha de papel—; lugar simbólico — posição do professor na relação pedagógica—; e lugar teórico —as ciências—.

Para Vidal (2005) estes alertas apontados por de Certeau marcaram as reflexões de R. Chartier que preocupou-se em dar ênfase nas interpretações remetendo-se ao conceito das representações sociais. Percebidas como práticas, as representações confrontam-se com a materialidade do mundo, na composição de corporeidades — modos de agir-, analisados principalmente por R. Chartier no que concerne à história da leitura, como por exemplo, ler em voz alta ou silenciosamente, fruto das relações entre os sujeitos e os objetos culturais postos à sua disposição.

A cultura material se refere aos múltiplos significados dos objetos, indo além de sua estrutura técnica e de sua função, envolvendo as relações sociais de que fazem parte, levando-nos a perceber o universo escolar na sua materialidade diversa e nas suas singularidades que caracterizam a cultura própria de cada tempo e espaço. Assim, conforme Castro:

Cultura Material Escolar pode abranger uma série de elementos que constituem o universo escolar, como os objetos de leitura e escrita (lápis, caneta, livros, etc.), materiais de limpeza (panos, vassouras, tapetes, etc), mobiliários (cadeiras, carteiras, bancos, mesas, etc.), indumentárias (fardamentos, chapéus, calçados, etc) dentre outros, os quais podem ser estudados sob perspectivas e ângulos teóricos e metodológicos diversos, inclusive sob um enfoque mais regionalizado. (2011, p.13)

Assim, qualquer objeto ou material disposto no universo escolar, ao possuir um significado próprio, imbricado nas dinâmicas sociais e culturais de determinado espaço ou ambiente, não será um simples utensilio neutro, homogêneo ou semelhante. Não está desatrelado das motivações particulares e coletivas dos diferentes grupos sociais que fazem parte daquele ambiente escolar, no qual segue pré-condições que são culturais, sociais, históricas e territoriais.

A pesquisa em cultura material manifesta, de acordo com Pesez (1990), materialidade associada à cultura, em que "a cultura material tem uma relação 
evidente com as injunções materiais que pesam sobre a vida do homem e às quais o homem opõe uma resposta que é precisamente a cultura" (1990, p. 180). Conforme, Felgueiras (2005), estudar a educação hoje significa prestar atenção à densidade histórica do sistema educativo, nos contextos concretos de realização, expresso numa cultura material que, simultaneamente, traduz as concepções de uma sociedade e manifesta as condições em que puderam ocorrer. De tal modo, a cultura material não se encontra numa relação de hierarquia em relação à cultura de um modo geral, haja vista que está influencia e influenciada pela outra.

Nesse sentido, como bem destaca Bencostta (2013), a cultura material apresenta uma ampla estrutura teórica com grandes potencialidades para a investigação histórica, representando uma grande aproximação com os estudos da nova história cultural. Assim, ao considerar as estruturas micro da cultura material escolar, frente à historicidade das estruturas macros que tratam dos fenômenos educacionais, ressalta a necessidade de inserir em ambas as escalas, os indivíduos em seus contextos sociais, possibilitando melhor interpretação das experiências destes na relação com o uso que fazem dos objetos e artefatos que constituem a materialidade da escola.

É necessário salientar que a emergência e consolidação do tema cultura escolar nas pesquisas em história da educação se dá ao mesmo tempo em que se amplia o diálogo com a chamada história cultural francesa. Uma das explicações para isso é que tanto a Cultura Escolar quanto à História Cultural contribuíram para a criação de um lugar confortável para a educação no terreno da cultura, não mais ancorado nos estudos sociológicos, mas historiográficos. Também virou lugar comum o entendimento que história cultural significa a de tradição francesa, proposta e realizada por R. Chartier.

Importa destacar que um pensamento materializado pela escrita, seja na forma de um livro, seja na forma de documento, carta, ou artigo, constitui o acervo histórico cultural de um povo, de um determinado grupo, ou de uma nação que, ao ser analisado, passa contar sua história. Com o propósito de elucidar à respeito da História Cultural, R. Chartier (1990) esclarece que "a história cultural é importante para identificar o modo como em diferentes lugares e momentos uma determinada realidade social é construída, pensada, dada a ler" (pp. 16-17). Portanto, ao voltar-se para a vida social, esse campo toma por objeto as formas e os motivos das suas representações, suas classificações e exclusões que constituem as configurações sociais e conceituais de um tempo ou de um espaço. 
Dessa forma, a História Cultural irá interessar-se pelos suportes de difusão e transmissão enquanto vetores das formas de cultura, estabelecendo seu campo na junção das representações e das práticas, e valorizando o sujeito agente também como sujeito pensante de sua história. Por conseguinte, foi dessa postura audaciosa e ampla da chamada Nova História Cultural que derivou outra maneira de pensar a história dos intelectuais, e mesmo a história intelectual, como uma história cultural sempre vinculada ao campo político.

Tais contribuições dos estudos de R. Chartier (1990) nos auxiliam a compreender a difusão do pensamento de autores em grupos específicos, ou no conjunto da sociedade. Sua ênfase na singularidade da leitura também nos remete à própria formação de leitor dos intelectuais aos quais dedicamos também nossas análises. Os leitores produzem sentidos singulares das suas leituras; os autores sistematizam ideias que serão lidas de forma singular pelos seus diversos leitores, cada qual com suas preferências, anseios, níveis de exigência e compreensão particulares. Mais do que pensar somente no específico de cada leitor, acreditamos que a abordagem proposta por R. Chartier é essencial para evitarmos considerações ingênuas sobre o pensamento ou a vivência dos nossos objetos de estudo.

\section{Os ideais de José Veríssimo e o Colégio Americano}

José Veríssimo Dias de Matos nasceu em Óbidos (Pará) em 1857. Estudou no Rio de Janeiro, onde voltou a morar até seu falecimento em 1916. Desenvolveu boa parte de suas atividades em Belém, onde fundou e dirigiu o Colégio Americano (1884-1890). Foi diretor da instrução pública neste mesmo ano e produziu uma série de atividades ligadas a produção de textos para revistas e jornais locais.

José Veríssimo nutria a convicção de que a educação escolarizada poderia contribuir para o melhoramento dos homens e ajudar o país a superar o atraso cultural, sendo estas considerações uma constante em seus escritos literários, apontando deste modo a importância dada à criação do Colégio Americano em 1884, na Província do Pará. Conforme França (2009), Veríssimo não explicita os motivos que o levaram a escolha do nome Colégio Americano, contudo ressalta que o colégio que criou seria uma casa de instrução e educação e não uma empresa mercantil.

O Colégio Americano é instalado no prédio do Dr. Cruz, na Estrada de São Jerônimo, no dia 07 de janeiro de 1884. Contudo, em 11 de agosto de 1887 
o colégio passa a funcionar no palacete do Sr. Bento Rabelo de Andrade, na Estrada de Nazaré, $n^{\circ}$ 49, um dos bairros mais nobre da cidade de Belém, possuindo mais de 1000 metros quadrado de quintal sombreado destinado ao recreio dos alunos. Os alunos eram crianças e jovens, logo a instituição oferecia os cursos primário e secundário (Idem).

Os cursos se organizavam da seguinte maneira: o curso primário estava organizado em quatro classes, que compreendia os ensinamentos de leitura e escrita, Língua Portuguesa, Cálculo e Aritmética, Geografia e História Geral; Coreografia da Amazônia; Geometria Prática e Desenho Linear. Enquanto que o curso secundário, também, organizado em quatro séries, preparava os alunos para o ingresso nos cursos superiores do Império. Somados a estes, em 1884, é anexado o Jardim de Infância, que estava voltado para meninos e meninas de 3 a 6 anos de idade, porém este curso durou apenas 3 meses (França, 2009, p. 115).

Em sua atuação no Colégio Americano, teve como propósito veicular as novas ideias do século que se materializaram nas reformas pedagógicas implantadas nesta instituição. Seus ideais pedagógicos estão baseado nas correntes positivistas e evolucionistas, que podem ser visualizados em seus escritos em Noticia Geral do Collegio Americano (1888).

Veríssimo em seus escritos procurava demonstrar a importância da educação moral associada à disciplina, tomando como aspectos fundamentais da formação do homem a educação física, a educação moral e os cuidados higiênicos, apontando inclusive para a importância da participação da família nesses processos. No referido documento, Veríssimo, em "Educação Moral, Regimento Interno e Disciplina" reitera:

EDUCAÇÃO - Além da formação do carater, desenvolvimento dos instintos altruístas, severa regulamentação dos costumes, tudo o que, em summa, constitue educação moral, que é objeto da maior solicitude por parte da Diretoria, as boas maneiras, a civilidade, são também assumpto de especial cuidado, esforçando-se o Collegio para que um alto sentimento de dignidade, de honra, de delicadesa, de sinceridade presida todas as relações do alumno, quer com seus mestres, quer com seus condiscípulos (Veríssimo, 1888, p.51)

Verificam-se os avanços obtidos no campo educacional a partir das considerações de Veríssimo, aplicadas na referida instituição escolar, que introduz a Educação Física e o Jardim de Infância no Brasil. As proposições de 
matriz positivista e evolucionista podem ser observadas na sua preocupação em trabalhar métodos de ensino que se adequem com o momento etário da criança. As suas inquietações se direcionam ao aprendizado da gramática, da história e da matemática, bem como as suas preocupações evidentes quanto à formação dos aspectos morais, respeitando a condição etária da infância. No Colégio Americano, tais ideais são praticados a partir de uma noção ligada aos preceitos de higiene, no qual os idealizadores de uma infância saudável e forte tinham como objeto de suas ações não somente o corpo, mas também a mente e a moral da criança.

Ainda de acordo com França (2004) esse caráter disciplinador e moralizador da educação física permeou as reflexões de José Veríssimo no Colégio. Somavam-se ainda as preocupações de natureza higienista e eugênicas. $\mathrm{O}$ próprio autor chama a atenção para o fato dessa educação ser tão importante quanto a educação moral e intelectual, visto que dela dependeria o futuro da família, da pátria e da humanidade. Ministrada em aulas regulares de ginástica, sob a direção de um professor habilitado e de exercícios militares dirigidos por um oficial do exército, jogos diversos como a barra, o piquete, o salto carneiro e as longas caminhadas compunham seu programa de estudos.

\section{Os objetos e materiais escolares do Colégio Americano}

De acordo com França (2004), no discurso proferido aos pais dos alunos por ocasião da inauguração do colégio, José Veríssimo chamava a atenção para o fato de que o único tipo de educação que pretendia oferecer aos alunos era a moderna, ressaltando que a distinção entre instrução e educação era moderna e que pertencia à ciência positiva. Os intelectuais que serviram de base para o delineamento das ações educativas a serem postas em prática no colégio eram aqueles que, no mundo europeu do século XIX, se voltaram à critica do modelo educacional ainda imperante, que privilegiava a educação clássica em detrimento da científica, e propunham um sistema escolar que se adequasse às novas exigências da sociedade da época, industrial, comercial e científica.

José Veríssimo, adepto desses valores, deixa entrever em várias passagens do seu discurso que pretendia introduzir, no colégio, um ensino de base científica, e outras formas de aprender e ensinar que tornassem o aprendizado mais atraente e favorecessem a compreensão, ao invés da mera decoração das lições.

As lições eram os meios sobre os quais se assentariam o desenvolvimento do ensino científico propalado por José Veríssimo. O ensino deveria 
partir da experiência, do concreto e do contato direto com os objetos do conhecimento. A cultura dos sentidos, como era conhecida, valorizava todo o conhecimento que se obtinha por meio das coisas sensíveis e da apreensão primeira do mundo exterior, contrapondo-se à forma convencional, até então em voga, de se ensinar com base na verbalização e nas verdades absolutas. Essa tendência a trabalhar com as coisas podia ser apreendida, por exemplo, na aquisição de materiais didáticos, muitos dos quais encomendados da Europa, na utilização de mapas, globos e atlas, na instalação de laboratórios apropriados, de recursos retirados da própria natureza, das caminhadas ao ar livre, etc. Todo um arcabouço pedagógico devia ser montado para aguçar a curiosidade das crianças.

De acordo com Castro (2011), os discursos pedagógicos instituem e organizam o universo escolar, determinando ações, comportamentos, relações, posições lugares epistemológicos- - Os discursos pedagógicos revelados no documento em análise deste estudo demonstram as relações existentes entre os diferentes sujeitos envolvidos no campo educacional e apontam para a ordenação do Colégio Americano, na perspectiva da constituição material da escola.

Considerando essa discussão, podemos dizer que a cultura material escolar no Colégio Americano, foi entendida como um conjunto de artefatos materiais que circulavam e eram usados no interior da escola, bem como a relação pedagógica que é intrinsecamente reveladora da dimensão social.

Ainda segundo Castro (2011), os estudos neste campo sobre a materialidade escolar, no contexto da escolarização primária nos possibilita pensar um leque variado de questões de pesquisa acerca do cotidiano da escola pública brasileira. Ao longo das análises foi constatada a existência de uma organização própria, no qual se extraiu os seguintes aspectos: 1) discurso pedagógico — como atente e pretende praticar o Colégio Americano—; 2) encerramento das aulas; 3) notas e boletins; 4) enxoval; 6) horário geral entradas e saídas-; 7) cuidados hygienicos.

Outro aspecto discutido por José Veríssimo, no Colégio, dizia respeito à disciplina. Apesar de o autor se colocar favorável à implantação de uma disciplina escolar que fosse ao mesmo tempo rigorosa e amável, que procurasse atuar mais pela ternura do que pela força ou pelo abuso do poder, os meios disciplinares por ele delineados estavam carregados de ações punitivas. Disciplinar e controlar eram as palavras de ordem a serem seguidas por todos aqueles envolvidos na formação das crianças. 
De uma maneira geral, a disciplina escolar proposta visava, antes de qualquer coisa, manter a ordem e a disciplina. Aos violadores das normas estabelecidas eram imputados severos castigos, que deveriam servir de exemplos para os demais; tudo em nome da ordem, da obediência, da submissão e dos bons costumes. Tratava-se de disciplinar as mentes, reorganizar as atitudes e os gestos, para a manutenção da ordem social.

Assim, foi instituído o tempo escolar com a finalidade de dirigir e controlar. Esse tempo de trabalho e de lazer era assim planejado por José Veríssimo:

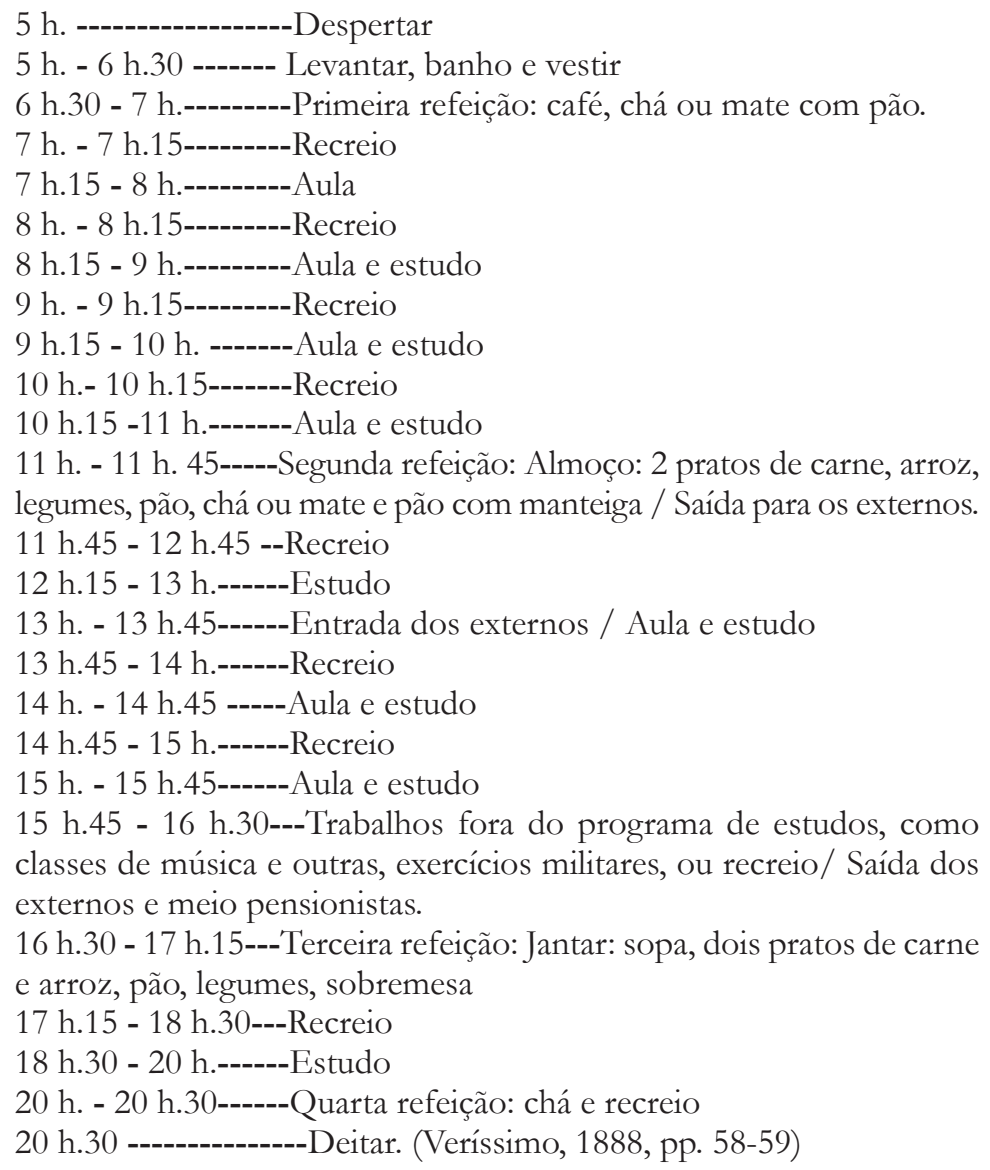

Somavam-se ainda as preocupações de natureza higienista e eugênicas. $\mathrm{O}$ próprio autor chama a atenção para o fato dessa educação ser tão importante quanto a educação moral e intelectual, visto que dela dependeria o futuro da família, da pátria e da humanidade. Ministrada em aulas regulares de ginástica, 
sob a direção de um professor habilitado e de exercícios militares dirigidos por um oficial do exército, jogos diversos como a barra, o piquete, o salto carneiro e as longas caminhadas compunham seu programa de estudos.

A preocupação com uma educação física promotora da saúde física e mental, regeneradora das virtudes e da moral revela o quanto o autor estava sintonizado com o pensamento médico- higienista da época, que em nome da "civilização", do "progresso" e da "ciência" ditava normas de condutas de "bem viver", contribuindo para a constituição de indivíduos saudáveis, úteis e disciplinados, para as funções específicas na produção. Sobre os preceitos de higiene o trecho seguinte revela que:

A saúde dos alunos é objeto do mais sério e perseverante cuidado.

O médico do estabelecimento, independente dos casos de moléstia, visita-o treze vezes por semana.

Quando a moléstia não for grave ou contagiosa, o alunno doente pode-querendo a família — ser tratado mesmo no collegio.

O edifício do Collegio situado num dos melhores bairros da capital, é alto e ventilado, e dispõe para recreio de mais de 1000 metros quadrados de quintal sombreado. É inteiramente caiado todos os anos, e os assoalhos lavados varias vezes.

Os dormitórios no andar superior, são muito arejados, sendo expressamente proibido conservar n'elles roupas servidas para as quaes tem o Collegio lugar apropriado.

Um systema completo de canalização d'aguas servidas, materias fecaes e outras, garante, tanto quanto possível de uma rigorosa hygiene.

A mobília escolar, bem como a distribuição da luz nas classes, quer de dia quer de noite, obedece aos preceitos de hygiene pedagógica, garantindo assim o menino de futuros desvios anatômicos ou afecções do aparelho visual, conforme se tem provado, são provenientes de uma mobília escolar defeituosa e de uma má distribuição de luz nas classes. (Veríssimo, 1888, pp. 54-55)

Observa-se que há toda uma organização didática e arquitetônica que visava possibilitar uma formação saudável e higiênica das crianças que ocupavam o referido espaço escolar, haja vista que este espaço também poderia se constituir em ambiente familiar para aquelas crianças, no qual o não atendimento de tais exigências e orientações também era apontado como responsável por desvios anatômicos dos infantes. Assim, também, aspectos revelados pela análise da obra indicam a materialidade da escola no que se refere à escolha do enxoval a ser utilizado pelos alunos do colégio, revelando a organização das práticas seguindo a mesma ordem de importância dos debates teóricos. Observa-se a relação do referido enxoval: 
Os alunos internos devem ter:

1 Fato completo de flanela preta, paletot fechado, calça e colete

1 Chapéo baixo de feltro preto

12 Camisas brancas com punhos e colarinhos (não se admitem nem

punhos nem colarinhos postiços)

6 Ceroulas (para os maiores de 10 annos)

12 Pares de meias

12 Lenços

6 Jaquetões de brim pardo

6 Calças de dito

6 Toalhas felpudas para banho e rosto

6 Fronhas brancas $(0, \mathrm{~m} 50) \times(0, \mathrm{~m} 40)$

3 Lençóes $(2 \mathrm{~m} \times 1 \mathrm{~m})$

3 Colchas de chitão encarnado forrado de morim $(2 \mathrm{~m} \times 1 \mathrm{~m})$

3 Camisões de dormir

3 Gravatas pretas

2 Saccos para roupa suja

1 Camisa de flanela para gynnastica (modelo do Collegio)

1 Dita comum para dita

2 Calças brancas

1 Pente de alisar

1 Dito fino

1 Escova de fato

1 Dita de cabello

1 Dita de unhas

1 Dita para dentes

1 Thesoura de unhas (Veríssimo, 1888, p. 60).

A necessidade de se descrever os detalhes que deveriam ser seguidos nas vestimentas dos alunos demonstra a importância assumida naquele contexto às questões que se referem à higiene e à disciplina. A necessidade de seguir os preceitos da higiene exigia uma boa apresentação nas vestimentas que deveriam ser brancas, ter os cabelos bem penteados e unhas limpas. Ao mesmo tempo em que já preparava as crianças e os jovens para uma vida regrada, tornando-os atentos a sua forma de apresentação, preparando-os desde cedo para as boas regras de conduta.

Neste sentido, as intenções de inserir no Colégio Americano uma noção de educação pautada nos princípios da modernidade, não estaria simplesmente circunscrita às intenções de construir novos referenciais teóricos e intelectuais no planejamento didático da escola. No discurso apresentado por José Veríssimo sobre a necessidade de um aparato material moderno, percebe-se a necessidade de adotar no Colégio Americano, os melhores e mais atualizados 
objetos materiais, sem os quais o projeto de escolarização dos alunos tornar-se-ia comprometido para o avanço da modernização e civilidade, ora almejadas pelos projetos sociais e interesses políticos relacionados às inovações pedagógicas daquele contexto.

\section{Considerações finais}

Na breve incursão teórica realizada no presente estudo sobre a cultura material escolar nos permite identificar que esta tem como horizonte a percepção das articulações dos materiais e objetos dispostos no ambiente escolar com os aspectos ligados ao contexto histórico, cultural e social em que foi engendrado. Logo, os artefatos não seriam simples objetos e utensílios, mas sim revelam as relações conflituosas ou pacíficas de determinados contextos, nos revelando inclusive às práticas escolares.

Observa-se que a utilização e descrição dos objetos dispostos na estruturação do Colégio Americano, para o seu idealizador, tinha como objetivo estabelecer e realizar a manutenção de normas que tinham como intenção formar alunos disciplinados, estando diretamente articulados com as intenções de educação física, moral e cívica dos infantes e dos jovens de até dezesseis anos de idade.

Assim, ao longo do corpus observamos que os objetos descritos e apontados, correspondiam ao um momento histórico em que estava emergindo um novo modelo de educação que enfatizava como importantes os aspectos da civilidade, da nação e da moral. Pontuar aspectos como o higienismo e a eugenia no pensamento de José Veríssimo, contidos nas matrizes cientificistas que permeavam o seu trabalho, nos permite compreender as motivações do educador ao idealizar o Colégio Americano, assim como as intenções do mesmo em descrever e caracterizar cada objeto e material na obra Noticia Geral do Collegio Americano. Tal debate associado à incursão teórica sobre a cultura material nos permite perceber que as suas escolhas no que se refere aos horários de entrada e saída, até à escolha do "enxoval" dos alunos estão na mesma ordem de importância dos debates sobre as opções teóricas do educador, nos revelando as práticas escolares que eram estabelecidas no referido Colégio.

\section{Fonte documental}

Veríssimo, J. (1888). Noticia geral sobre o Colégio Americano. Pará: Tipografia de Pinto Barbosa \& Cia. 


\section{Referências}

Bencostta, M. L. (2013). A noção de cultura material escolar em debate no campo de investigação da história da educação. Em C.A.Castro (Org.) Cultura material escolar: a escola e seus artefatos (MA, SP. PR, SC e RJ)- 1870/1925. São Luís: EDUFMA: Café \& Lápis.

Castro, C.A. (2011). Os usos e as tipologias dos materiais escolares no Maranhão Oitocentista. Em C.A.Castro, C. Cury, A. Lospes, \& A.C. Pinheiro (Orgs.) Objetos, práticas e sujeitos escolares no Norte e Nordeste. São Luís: EDUFMA, UFPB, Café \& Lápis.

Certeau de, M. (1994). A invenção do cotidiano - Artes de fazer. Petrópolis: Editora Vozes.

Chartier, R. (1990). A bistória cultural: entre práticas e representações. Rio de Janeiro: Editora Bertrand Brasil.

Chartier, A. (dezembro, 2000). Fazeres ordinários da classe: uma aposta para a pesquisa e para a formação. Educação e Pesquisa, 26(2), 157-168.

Chervel, A. (1990). História das disciplinas escolares: reflexões sobre um campo de pesquisa. Teoria \& Educação, (2), 177-229.

Faria, L.M., Gonçalves, D., Gonçalves, I., \& Paulilo, A. (janeiro-abril, 2004). A cultura escolar como categoria de análise e como campo de investigação na história da educação. Educação e Pesquisa, 30(1), 139-159.

Felgueiras, M. (janeiro/abril, 2005). Materialidade da cultura escolar. A importância da museologia na conservação/comunicação da herança educativa. Pro-Posições, 16(1) (46), 87-102.

Forquin, J. (1993). Escola e cultura: as bases sociais e epistemológicas do conhecimento escolar. Porto Alegre: Artes Médicas.

França, M. (2004). José Veríssimo (1857-1916) e a educação brasileira republicana: raízes da ren ovação escolar conservadora (Tese Doutorado em História e Filosofia da educação, Universidade Estadual de Campinas, Campinas, Brasil).

França, M. (2009). O pensamento e a prática escolar de José Veríssimo no Colégio americano (1884-1890). Revista Cocar - V.3. n. 6, 113-124.

Julia, D. (janeiro-junho, 2001). A Cultura Escolar como Objeto Histórico. Revista Brasileira de História da Educação, (1), 9-43.

Pesez, J. M. (1990). A história da cultura material. Em J. Le Goff, E. Le Roy, \& G. Duby (Orgs.), A nova história. Coimbra: Almedina.

Vidal, D. (2005). Cultura e prática escolares: uma reflexão sobre documento e arquivos escolares. Em R. de Souza, \& V. Valdemarin (Orgs.), A cultura escolar em debate: questões conceituais, metodológicas e desafios para a pesquisa. Campinas: Autores Associados.

Viñao, A. (2008). A história das disciplinas escolares. Revista Brasileira de História da Educação, 8(3), 174-208. 